\title{
Parecido, mas não igual: Proyecto Filoctetes e Project Embed - processos distintos, resultados semelhantes
}

\author{
Christiane de Fátima Martins \\ Mestranda em Artes Cênicas/USP \\ Área de Concentração: Teoria e Prática do Teatro \\ Orientador: Felisberto Sabino da Costa \\ Bolsista CAPES
}

\begin{abstract}
Resumo: A partir da análise comparativa das obras Proyecto Filoctetes, de Emílio García Wehbi, e Project embed, de Mark Jenkins, este projeto tem por objetivo discutir o hibridismo nas produções artísticas contemporâneas e suas nomenclaturas, principalmente a intersecção entre as Artes Cênicas e as Artes Plásticas, como a performance arte, que ocorre no trabalho desses dois artistas, com trajetórias, formações (linguagens artísticas) e nacionalidades distintas, mas que produzem obras semelhantes.
\end{abstract}

Palavras-chave: contemporaneidade, intervenção urbana, performance arte, teatralidade

Title: Similar but not equal: Proyecto Filoctetes and Project Embed - distinct processes, similar results

Abstract: From the comparative analysis of the works Proyecto Filoctetes, by Emilio García Wehbi, and Project Embed, by Mark Jenkins, this research aims to discuss the hybridism in contemporary artistic productions and their nomenclatures, especially the intersection between Scenic Arts and Visual Arts, like the performance art, which occurs in the work of both artists with different trajectories, formations (artistic languages) and nationalities, but who have produced similar works.

Keywords: contemporaneity, performance art, theatricality, urban intervention

Título: Semejantes pero no iguales: Proyecto Filoctetes y Project embed - distintos procesos, resultados similares

Resumen: A partir del análisis comparativo de las obras Proyecto Filoctetes, de Emilio García Wehbi y Proyecto embed, de Mark Jenkins, este proyecto tiene por objetivo discutir el hibridismo en las producciones artísticas contemporáneas y sus nomenclaturas. Principalmente la intersección entre las Artes Escénicas y las Artes Plásticas, como la performance arte que ocurre en el trabajo de estos dos artistas, con trayectorias, formaciones (lenguajes artísticos) y nacionalidad distintas, pero que producen obras semejantes.

Palabras-clave: contemporaneidad, intervención urbana, performance, teatralidad

Desde a década de 1920, muitos artistas buscam a integração das artes, retomando de forma extremamente favorável a ideia de uma arte total, conforme havia sido sugerida pelo alemão Richard Wagner, que buscou unir, em suas óperas, elementos do teatro, da dança, da música e das artes plásticas, no final do século 19. Hoje, com o surgimento de linguagens artísticas consideradas híbridas, a integração de elementos das linguagens tradicionais soa como uma consequência natural, 
sendo essa a razão por ter-se criado formas de expressões como o happening, a body art, a land art, a performance art, entre outras.

Neste artigo, concentraremo-nos nos aspectos referentes à performance arte e à intervenção urbana, realizando a ligação dessas linguagens com as tradicionais Artes Plásticas e Artes Cênicas. Para tanto, teremos como referência duas obras específicas: o Proyecto Filoctetes, criado pelo diretor argentino Emilio García Wehbi, e o Project Embed, do artista plástico norteamericano Mark Jenkins.

O Proyecto Filoctetes, de Emilio García Wehbi, foi realizado em Viena (Áustria), Buenos Aires (Argentina), Berlim (Alemanha) e Cracóvia (Polônia). Apresenta-se como uma crítica social, confrontando a globalização, no sentido de criar um evento artístico de contestação social sobre algo que está tomando proporções maiores, possivelmente, por ser uma das conseqüências do projeto de globalização econômica. Ao mesmo tempo, procura-se criar um projeto global que possa ser realizado em qualquer cidade do mundo, já que toda cidade esconde aquilo que ela crê que não lhe serve (causa e efeito da invisibilidade pública).

A intervenção urbana consistiu na construção de cerca de 23 bonecos, corpos hiperrealistas de látex, para a intervenção em Viena e Buenos Aires, e 22 bonecos para a intervenção em Berlim e na Cracóvia. Esses bonecos foram instalados durante o amanhecer nessas cidades em posições que aparentassem desamparo, ou que sugerissem a ocorrência de um acidente. Por debaixo das roupas de alguns dos bonecos, havia aparelhos de áudio que emitiam sons, como por exemplo, o de alguém dormindo.

Essa ideia chegou a García Wehbi por meio do contato com o trabalho de fotografia do ucraniano Boris Mikhailov, que tem sua produção focada na duplicidade existente entre o sistema político e social, em que a câmera, segundo Mikhailov, não é somente um instrumento de trabalho, mas também funciona como um "registrador" da verdade.

Já o Project Embed, de Mark Jenkins, surgiu como uma continuação do Tape men project, inspirado no trabalho do artista espanhol Juan Muñoz que, na década de 1980, passou a criar esculturas de figuras humanas e a instalá-las em lugares urbanos. Foi o sentido crítico e surreal dado às obras de Juan Muñoz que inspiraram Mark Jenkins (desejoso de trabalhar com intervenção urbana), a criar os "homens de fita" e a espalhá-los no meio urbano. Gradualmente, esses bonecos ganharam novas perspectivas até deixarem de fazer parte do Tape men project, dando início ao Project embed. Neste momento, Jenkins decidiu tornar a obra mais realista, vestindo suas esculturas - feitas, principalmente, com embalagens plásticas e fitas adesivas -, o que possibilitou criar uma 
maior e mais diversificada reação nos transeuntes e nas autoridades que com elas se deparavam.

Jenkins costuma dizer que vê a rua como um palco, onde os passantes são transformados em espectadores. Defende o uso da rua como um espaço de miscigenação, tanto de atores sociais quanto de manifestações artísticas. Enfim, um espaço onde a hibridização é possível e permissível.

O Project embed teve início no ano de 2003, na cidade do Rio de Janeiro, quando Jenkins iniciou a construção das primeiras peças das esculturas, que foram feitas a partir de moldes tirados do corpo do artista e de sua namorada. O trabalho de Jenkins já circulou por cidades como Washington DC, Nova Iorque, Londres, Barcelona, Malmo, Los Angeles e Palestina.

Mesmo com o intuito de criação e com referências totalmente divergentes por parte desses dois artistas, ambas as obras possuem similaridades facilmente perceptíveis, como a utilização do espaço público e urbano, o uso hiper-realista de bonecos e, de certa maneira, seus efeitos sobre os transeuntes, que são transformados em espectadores no momento em que direcionam e têm seu olhar captado pela presença do boneco. ${ }^{1}$

Por atuar no espaço público, tais obras tornam-se intervenções urbanas; ou seja, elas interferem no fluxo do cotidiano da paisagem e, consequentemente, influenciam o trajeto do passante. E, ao se pensar em espaço público, a rua torna-se um lugar recorrente, já que lá se dão múltiplas relações e eventos. É na rua que, muitas vezes, ocorrem inversões de papéis, de posturas, de condutas que, no âmbito familiar, não são permitidas ou explicitadas. É o espaço onde encontramos a alteridade, dos outros e de nós mesmos. Lugar de revelação e rebelião onde tudo é permitido. Contudo, nela também há o paradoxo da permissividade, pois, ao mesmo tempo em que é livre e aberta para todos, sofre uma série de regulamentações que incorporamos no nosso cotidiano, aceitando-as e legitimando-as.

Além disso, há o olhar artístico sobre o espaço urbano em que, como coloca Henri Lefebvre (2008), ${ }^{2}$ a cidade deve ser vista a partir de seu duplo aspecto: no primeiro, é preciso perceber a cidade através dos diversos monumentos que a modelam, ou seja, que definem sua imagem; no segundo, atenta-se ao emprego do tempo na vida urbana conferido pelos seus cidadãos, além de se enfatizar a multidisciplinaridade de olhares voltados para a cidade, para o seu espaço físico.

Retomando as obras de Wehbi e Jenkins, percebemos que esses artistas fazem com que a arte, inserida no espaço urbano, integre o cotidiano da cidade e de seus habitantes, colocando-os em uma espécie de confronto reflexivo, por meio da aproximação entre a obra de arte e seus espectadores, não impondo limites entre ambos, e sim intensificando esse encontro. Dessa maneira, 
cria-se momentos de reflexão tanto acerca do que diz respeito ao fazer artístico quanto do lugar e dos papéis que a arte, o artista e os espectadores ocupam na sociedade.

Quanto à utilização de bonecos/esculturas no lugar de atores/performers, no caso do Proyecto Filoctetes, García Wehbi decidiu utilizá-los por acreditar que somente um boneco poderia transmitir a "sensação de morte" desejada. Diferentemente de um corpo vivo que, para Wehbi, seria incapaz de produzi-la. Em uma palestra dada em Kyoto, no ano de 2005, García Wehbi explicita essa sensação que desejava provocar e como isso foi recebido:

[...] um ator não poderia representar a morte com a mesma conviç̧ão de um objeto sem vida própria. $\mathrm{O}$ objeto não teme a morte, ele a simboliza de uma forma radical e contundente; "é" a morte, não a representa. Por outro lado, o espectador pressente a morte no cenário (WEHBI, 2005, p. 1). ${ }^{3}$

O projeto aparece como politicamente incorreto ante os olhos do tecido social porque joga com o conceito de obscenidade (o que está fora de cena, o que uma sociedade se nega a ver), neste caso a morte. O corpo morto ou caído do boneco na via pública provoca um memento mori (uma evocação da morte) no transeunte que, através dessa irrupção secreta do espaço público, se transforma em ator. O tema da morte é obviamente um tabu na maioria das sociedades, e só se aceita seu tratamento artístico de forma altamente metaforizada. Por isso, o Proyecto Filoctetes é rejeitado. Porque dissimula a metáfora, de modo que ela apareça como realidade (WEHBI, 2005, p. 9). ${ }^{4}$

Já Mark Jenkins, como dito anteriormente, criou o Project embed por influência de seu trabalho anterior intitulado Tape men, no qual a figura humana era recriada com fita adesiva. Nesse caso, podemos pensar na transformação do material, na maneira em que o simples fato de vestir estas esculturas de fita, com as mesmas roupas usadas por cidadãos comuns, modificou seus signos aos olhos das pessoas. Simples indumentária acrescida de volume foi capaz de despertar a curiosidade e, até mesmo, de chocar o transeunte, ao ver um elemento tão semelhante a si mesmo em posições inverossímeis, como por exemplo, a escultura que simula alguém com a cabeça atravessando uma parede.

Essas performances lidam com um elemento que é a mudança da condição do espectador, já que, nessas obras, ele se torna o ponto central da apresentação. Em outras palavras: o espectador transforma-se tanto em objeto quanto em sujeito da obra, que só se realiza enquanto tal no momento em que ocorre o contato direto entre ambos. Contanto que possibilite ao espectador uma função mais ativa e reflexiva diante da obra de arte. Tudo isso se potencializa com o uso do boneco/escultura que, apesar de ser inanimado, não se transforma em um ser sem vida. Mesmo que não tenha sido uma ideia dos artistas, os bonecos/esculturas utilizados nessas obras podem ser relacionados com o boneco/objeto do teatro de animação, pelo fato de que podem ser manipulados e 
possuir anima, ${ }^{5}$ o que já são de certa forma, visto que integram a paisagem e assumem personagens dentro dela.

Além disso, como Carlos Converso afirma, nesse tipo de teatro os objetos podem ser utilizados como aquilo que realmente são, ou como elementos significantes, isto é, como símbolos ou metáforas, em que os “objetos não só pretendem desempenhar a função de personagens a partir de sua animação, senão também o de objeto como tal, estático, como signo que aduz informação ao contexto geral da cena" (2000, p. 96). ${ }^{6}$

A opção pela utilização de bonecos/esculturas no lugar de atores pode se dar pela duplicidade encontrada no uso do objeto estático. Conforme Maryse Badiou, o objeto "pode transmitir através do movimento, a expressão máxima da vida humana, porque participa do mundo da matéria inanimada - e da morte - e do universo do sujeito, e da vida" (1992, p. 10). São figuras inanimadas, pois destituídas de movimentos; contudo, possuem, aparentemente, vida própria por assumirem proporções, feições e posturas semelhantes (se não iguais) aos dos seres humanos.

Encontra-se exatamente neste ponto a característica que legitima tais trabalhos como artísticos: a capacidade de entrelaçar elementos reais com elementos irreais, localizando-se o real no que existe de concreto, e o irreal no que é capaz de reverberar no espectador, sua recepção. Assim, o boneco/escultura, seja de fita ou de látex, é um objeto material, real, mas sua figura no estado em que é colocado, mesmo que, de certa maneira, reproduza imagens do nosso cotidiano, provoca uma estranheza, um estado de além-vida.

Por meio de suas obras, ambos os artistas criaram uma atmosfera capaz de provocar reflexões acerca de quem somos e de nosso corpo, que é tão precário e sensível. Vai além do cruzamento de linguagens artísticas. Mesmo que desprovidos de intencionalidade, tratam do homem e seu lugar na sociedade, sobre quem somos e como nos comportamos, sobre nossos modos de ser e estar no mundo.

Talvez a vontade primeira de Emilio Garcia Wehbi, com o Proyecto Filoctetes, e de Mark Jenkins, com o Project embed, tenha sido o processo artístico: mesclar linguagens, fazer uso do objeto tendo o espaço público e urbano como cenário. Contudo, suas obras podem levar a inúmeras discussões não só no campo das artes, mas também no de disciplinas como sociologia, antropologia, política, psicologia, entre outras.

As intervenções urbanas performáticas de Emilio García Wehbi (Proyecto Filoctetes) e de Mark Jenkins (Project embed), além de poderem ser caracterizadas como eventos artísticos, são, antes de tudo, performances sociais, pois interferem no espaço público das cidades onde são 
apresentadas, e ainda se constituem, por si só, em um evento comunicativo de reflexão crítica, que possui uma estrutura de participação, na qual a "alternância de turnos e a interação ator [performer] - audiência podem ter implicações profundas na formação das relações sociais" (BAUMAN; BRIGGS, 2008, p. 193).

Diante do exposto, conclui-se que, ao procurar localizar as semelhanças e diferenças entre as linguagens artísticas, apontando para áreas fronteiriças, em uma tentativa de divisão e classificação dos eventos artísticos, acabamos por gerar uma grande limitação das áreas abordadas neste estudo. Enquanto que, ao não realizarmos certas distinções, pode-se expandir os conceitos artísticos, permitindo, até mesmo, englobar essas novas formas de trabalho. Pressupõe-se então que a arte talvez esteja caminhando para um sentido amplo e unitário, no qual o artista pode ter plena liberdade de expressão, expandindo cada vez mais as fronteiras entre as linguagens em sua arte.

Assim, quando se fala do Proyecto Filoctetes e do Project embed, pode-se sim fazer referência à teatralidade, à plasticidade, ao teatro de animação, ao sujeito, ao objeto, à semântica, à sociedade, à economia; em suma, entramos em um campo de hibridez inegável.

Seria possível dizer ainda que com um - talvez singelo - gesto artístico, que propõe discutir o comportamento social, diversos artistas, como Emilio Garcia Wehbi e Mark Jenkins - que expõem bonecos hiper-realistas no espaço urbano -, estão confrontando, mediante uma linguagem estética, a realidade política e social, seja ela por meio de uma visão global ou local.

\section{Referências}

BADIOU, Maryse. As marionetes - A duplicidade do ser e não ser. Revista Malic, Barcelona, Teatro La Fanfarra - Teatro Malic, n. 2, 1992. (Trad. Valmor Beltrame)

BAUMAN, Richard; BRIGGS, Charles. Poética e performance como perspectivas críticas sobre a linguagem e a vida social. Ilha - Revista de Antropologia, Florianópolis, UFSC/PPGAS, v. 8, p. 185-229, 2006.

CONVERSO, Carlos. Entrenamiento del titiritero. México, D.F.: Escenología, A.C., 2000.

WEHBI, Emilio García. El Proyecto Filoctetes. Texto avulso. Palestra na Universidade de Kyoto. Japão, 2005. [Inédito]. 
${ }^{1}$ Ao contrário de Emilio García Wehbi, Mark Jenkins não trata as figuras humanas que produz como bonecos. Ele as chama de escultura. Por isso, optamos por utilizar os termos da forma em que são empregados pelo artista criador de cada obra.

${ }^{2}$ Lefebvre ainda expõe que a proximidade entre arte e cidade é muito maior do que imaginamos, assim como a ampliação de sua multidisciplinaridade, usando como exemplo o fato de que, já em janeiro de 1972, o Museu de Arte Moderna (MOMA), de Nova Iorque, realizou um simpósio reunindo linguistas, escritores, poetas, filósofos, semiólogos, sociólogos, entre outros, com o intuito de discutir um novo projeto que refletisse a mudança da sociedade industrial para a sociedade urbana.

3 “Un actor no podría representar la muerte con la misma convicción de un objeto sin vida propia. El objeto no le teme la muerte, la simboliza de una forma radical y contundente, 'es' la muerte, no la actúa. El espectador, por lo tanto, presiente la muerta en el escenario". [Tradução nossa].

4 "El proyecto aparece como politicamente incorreto ante los ojos del tejido social porque juega con el concepto de obscenidad (lo que está fuera de la escena, lo que una sociedad se niega a ver), en este caso la muerte. El cuerpo muerto o caído del muñeco en la vía pública provoca un memento mori (una evocación de la muerte) en el transeúnte, que a través de esta irrupción secreta en el espacio público se transforma en actor. El tema de la muertes es obviamente un tabú en las mayorías de las sociedades, y solo se acepta su tratamiento artístico de forma altamente metaforizada. Por eso, el Proyecto Filoctetes es rechazado, porque disfraza la metáfora de forma que aparezca como realidad". [Tradução nossa].

${ }^{5}$ Do latim: referente à alma, vida.

6 “objetos que no solo se pretende que desempenen la función de personajes a partir de animarlos, sino también el de objeto como tal, estático, como un signo que aporta información al contexto general de la escena. [Tradução nossa]. 